\title{
Analysis of Grade 10 English Textbook with Reference to Curriculum and Examination
}

Laxman K. C. Tribhuvan University, Nepal kumaikshetri2@gmail.com

\section{Abstract}

This paper entitled "Analysis of Grade 10 English textbook with reference to curriculum and examination" was an attempt to explore the relationship among curriculum, text book and examination system. It aims to explore the contents in the textbook which were assumed by curriculum and evaluation procedures specified in the examination system. The contents and exposure sufficiency to develop intended language competency in learners were attempted to analyze. Another important concern of this paper was to explore the opinions of school level English teachers, who are the keys to materialize the textbook in relation to curriculum and examination system. Phenomenological research design was used in the study and the data was collected through interview, group discussion and interaction. The collected data were critically analyzed by developing themes. The findings of the study depict that there is insufficiency of the contents in the prescribed textbook for grade 10 in the experience of teachers and students. Similarly, they also noted that the contents are not suffice to achieve the objectives of the curriculum.

Keywords: sufficient contents, exposure, curriculum approach, competency

\section{Introduction}

There is a close relationship amid curriculum, textbook and examination. Without collaborative execution of textbook with reference to curriculum and examination, the objectives of the curriculum cannot be achieved. Textbook is one crucial aspect of curriculum materialization and processing. Specifically, school level students are not able to have access to the reading materials which are supposed to be consulted by the students. In the context of Nepal, I have experienced that English textbooks at school levels specifically in community schools are not able to incorporate the sufficient materials to enhance their learning level as intended by the respective curriculum.

The national level examination is taken at the end of grade ten. Many students fail or obtain low grade in compulsory English subject. Out of 33 students, 6 obtained grade $\mathrm{D}, 10 \mathrm{D}+, 8 \mathrm{C}+, 4 \mathrm{~B}, 3 \mathrm{~B}+$ and $2 \mathrm{~A}$ in compulsory English in a secondary 
school A, Kirtipur in 2075 BS in SEE. Another important matter is the students who obtain pass grade in Secondary Education Examination in English will have poor performance in grade 11 and 12 . Out of 172 students, 27 obtained grade $E$, 29 D, 57 D+, 35 C, 14 C+, 6 B, and 4 B+ in compulsory English in secondary School $B$, Kirtipur in 2076 BS in grade XII in the result published by National Examination Board (NEB) , Bhaktapur, Nepal ( NEB, 2076). Similarly, in the internal examination administrated by secondary school B for grade XI in 2075 BS, in education faculty out of 32 students 14 obtained grade E, 5 D, 2 D+, 7 C, 2 C+ and 2 B in compulsory English. There are some shortcomings in evaluation system. Due to such shortcomings students passing rate to some extent is higher than what really ought to be in case of grade $X$ or SEE because of nature of examination that test items are more objective in which the poor learners prone to copy the answer from other good learners. This causes the result gap between SEE, and grade XI and XII in compulsory English. Nowadays, the policy of government is the students who have poor grade in mathematics, science and English are allowed to get admission in major English and other general subjects in education faculty which encourages poor performing students to study English as major subject. Students who are able to obtain minimum pass grade D+ in SEE are eligible to get admission in major English in grade XI. If a student obtains D+ grade in English and 1.6 GPA, he/she is eligible to study English as major subject, (Curriculum and Training Division, HSEB, 2016). Out of 172 students, 56 of them obtained D and E grade in grade 12 in compulsory English in Secondary School B Kirtipur in the examination administrated by NEB in 2075 BS. It has created the challenge in teaching and learning major English in higher level too. Students do not choose their major English with their due interest but they do so with last alternate. NEB result 2076 BS for grade XII in major English shows that out of 36 students 3 obtained grade $B, 4 C+, 13$ C, 12 D+, 3 D and $1 \mathrm{E}$ (NEB, 2076). These all situations motivated me to study on it. This is just an opening issue. Scholars may have conducted research on English textbook but a few researches (e.g. Mukundan, 2007; Meidani \& Pishghadan, 2013) have explored this phenomenon. However, sufficient studies have not been done yet. We find many cross-cutting issues which should further be studied.

Still, there is a dire need of conducting studies in language teaching in relation to the textbook, curriculum and examination system. How students and English teachers in community schools are experiencing in their learning and teaching abiding the English textbook and its materials of grade $X$ and to what extent the English textbook is able to expose teaching learning material to achieve the goal of curriculum that objectively examined in SEE nationwide are the problems stated in this study. 


\section{Study Design}

This study was designed to examine the grade 10 English text book in relation to curriculum and the examination. Various documents and publications related to the topic were consulted as the secondary sources to develop the theoretical support. The results from two schools were collected: one secondary school that is up to grade $X$ and another secondary school up to grade XII which were named as school $A$ and school $B$ respectively in this paper. Three secondary level English teachers who were teaching in schools were selected purposively and interviewed with unstructured techniques/ interview model to get their experiences, ideas and opinions regarding the sufficiency of English textbook. Similarly, the lived experiences of grade 10 students from three government aided schools in Kirtipur have been included considering as the relevant information for the study.

Since I have been teaching English for 10 years and have the lived experience on the phenomenology, in this study, I devised phenomenological research design including interpretative critical research paradigm with blending. Here, materials consulted and individuals interviewed were interpreted and critically analyzed to draw the essence. Conclusion was made on the basis of interpretation and critical analysis.

\section{Results}

Since it is a phenomenological research, at first, I had the lived data regarding the phenomenon. Similarly, I collected data on the phenomenon from the three secondary level English teachers through unstructured repeated interview and discussion. Results from two secondary schools were also collected to analyze. In the course of data analysis due attention was made to draw the essence of experience, observation, interview and discussion on the phenomena. This was less studied phenomenon in the context of Nepal. The results of the study have been subsumed in the following categories:

\section{English Language Curriculum}

Curriculum is a foundation of teaching and learning planning. Curriculum provides frame works for tutorial and hidden guidelines for natural teaching and learning for concerning of teaching and learning contents, evaluation schemes and level of learning on particular subject/discipline.|"Curriculum is a design to control or find the contents of a particular subject,"(Kelly, 2004, cited in Karki, 2014, p.90). We have infinite contents of knowledge, it is almost impossible to teach and learn all of them; we should therefore be specific and selective on particular 
contents to make them teachable and learnable reference to time, means and resources, needs and doctrine of teaching, learnability and practicality.

"Curriculum as an educational program states the purposes and also the content teaching procedures and the learning experiences necessary to achieve these purposes,"(Karki, 2014, p. 88). Curriculum is developed with purpose; it has broadly social purposes and specifically individual purposes to be enhanced in the subject matter exposing various contents through formal educational processes.

"The curriculum embodies the knowledge and skills with which a nation or other jurisdiction or institution intends to equip its children and youth so that they are ready to assure adulthood in an engaged, productive and fulfilling way," (Muskin, 2015, p.4). Curriculum is planned to promote the life chances of individuals. Curriculum includes who to tech, what to teach, how to teach what to use in process how to measure how effective our teaching and learning are Curriculum is supposed to bring new outcomes in learners. Curriculum is a total guideline learning experiences designed to facilitate learners learning for establishing quality relationship between what is learnt and what operates, outside the school. Here curriculum is broadly what is taught and learnt school and its relation with other experiences which are out of school. Curriculum has therefore concrete and abstract aspects. It's the inseparable aspect of formal and planned education.

In English language education, curriculum is the planned outline about why to teach, what to teach, how to teach, what to use, how to evaluate the plan or entire goal of teaching and learning regarding language behaviors changes in target learners. Curriculum development is a systematic planning, development and review practices in all aspects of a language program to improve the quality of language teaching. It includes learners' needs, objectives to address the needs, appropriate syllabus, course structure, teaching methods and materials, and evaluation system of the language program (Calub, 2018).

Curriculum in English language tells us why, what and how we are going to learn English. Curriculum signifies the purpose of English learning. Planning English language curriculum means creating a complex blend of literature lesson, language, skills learning and writing activities, (Loop, 2019). Language and society are inseparable aspects; language origins, develops and decays in society. Language is used to symbolize and signify the various contents in human world. Learning and teaching language is to make the learners to be able to communicate various ideas and contents each other mutually. Moreover learning language 
is a process of being socially accountable, responsible and attributive person. Language curriculum therefore aims to bring and blend various contents which contain the language as exposure to learners to develop language competency including social processing knowledge and behaviors in learners. In language learning there is collaboration language skills as well as skills to use language in different settings of its use as discourse competence.

Every curriculum has its purposes. "The purpose of English language curriculum should be to develop the personality of the students and enable them to face the challenges of their future lives and to participate in the process of globalization," (Singh, 2015, p.1). Definitely present era of world development is globalization and one influencing factor is language. There are some principles of curriculum constructions in English language. Singh (2015) further adds 8 principles as: principle of interest, principle of vividness and flexibility, principle of activity, principle of unity, principle of correlations, principle of individual differences, principle of maxim of teaching, and principle of proper use of leisure.

In the context of Nepal, English is taught as foreign language. Its main goal is to educate the Nepalese learners as global members by using the English as an international or foreign language. "Teaching English language and literature in Nepal is of about a half a decade, starting from the mid twentieth century,"(Bista, 2011, p.1). It is about a half century even if Bista wrote decade. In very much limited situation, English was used to teach in Nepal during the king Pratap Malla's regime in Malla dynasty, (Bashyal, 2018 ). Formally English language was started to teach with the beginning of Rana Regime then the Prime Minister Junga Bahadur Rana. English language has been incorporated in curriculum from grade 1 to Bachelor in some academic streams as compulsory course. "English is already taught from Grade 1 and gradually becoming a de facto medium of instruction in public schools..., (Phyak, 2016)". The constitution of Nepal 2015 does not have any explicit language policies regarding education except education in mother tongue (Government of Nepal, 2015) up to primary level. With this many government schools are shifting from Nepali medium to English medium, (Rana, 2018). Unfortunately, there are several problems and challenges to achieve the goal intended by national curriculum. Secondary level, grade IX and X has compulsory English. By nature of curriculum, it has focused on communicative approach of language teaching and learning. Curriculum has included various communicative forms and functions. Government of Nepal minister of Education, Department of Education, and Curriculum Development Center has developed curriculum and text book of English. 


\section{English Textbook}

A text book is a compilation of collected materials for the convenience of learners and teacher to meet the objectives of curriculum. A textbook contains facts contents and it is used by target learners of particular subjects as the contents and various teacher learner activities to facilitate their teaching learning process as the techniques and methods. "Textbooks are key components in most language programs. In some situations they serve as the basis for much of the language input. Learners receive and the language practice that occurs in the classroom, "(Richards, 2001, p. 1). A text book is written according to the syllabus and gives the outline of the course. A good text book takes into consideration the method of teaching and level of readership. It is revised keeping in view new development and changing methodology of teaching.

The textbook includes content, methods, practices illustration physically and teachability and learnability psychologically. Textbook is designed considering the theory of learning, theory of teaching and theory of changing or revising and theory of assessment on the particular subject matter or subject. In most of the cases text book tells us what to teach and how to evaluate/ assess our teaching and learning effectiveness. Most of the teachers therefore totally rely on textbook specifically in school level. "I also observed that these were contexts where teachers simply depended on the textbooks for their lifetime," (Karki, 2014 , p. 89). As Tomlinson (2001, as cited in Anjaneyulu, 2014, p. 2.) states that the proponents of the course book argue that it is the most convenient form of presenting materials, it helps to achieve consistency and continuation, it gives learners a sense of system cohesion and progress and it helps teachers prepare and learners revise". In developed countries where teachers are well trained and students and teachers both have good access of teaching learning materials in English language teaching learning, the dependency on textbook to achieve the goals and objectives of English is rare or low. Although there are many other learning materials available in this period, research in wealthy nations shows that the vast majority of teachers still continue to rely heavily on the textbook as their core teaching resource. On the contrary, country like Nepal the teachers are not well trained; guardians awareness level is low; teachers and learners accessibility to material is in neglecting level and government agencies who are supposed to develop curriculum write textbook and deliver it to the target learners in schools has the great challenges to achieve the goal of curriculum and intended level of English language development. "Despite the impacts of new technologies, textbook will doubtless continue to play an important role in language teaching and provide a useful resource for both teachers and learners, "(Richards, 2001, 
p. 6). In this regard, one of interviewees states:

Our curriculum has devised communicative approach but the setting and infrastructure that we have for teaching and learning English do not support it we need language lab, as other computer and science lab regarding this curriculum is mute.

Similarly, a student from class 10 stated, "We read this book but in the examination only 15 marks questions will be asked". This implies that students do not believe that they would not pass their exam depending on the designated textbook of English. There are various benefits for elementary or school level learners to have textbook for their managed and guided learning which is essential for them. "... the textbook is a cost-effective way of providing the learner with security, system, progress, and revision, and that at the same time it saves the teacher precious time and provides resources to base the lesson on," (Tomlinson, 2012, p. 271). The texts which are mentioned in textbook and supposed to develop reading comprehension skills in learners are not sufficient. They do not expose enough reading opportunities that can develop various reading skills in learners.

The grade 10 English textbook is published by curriculum development center including the contribution of various writers and university professors. This has copy right. This has 19 units including various texts under various communicative functions are mentioned including various reading texts in inclusive way. These exercises following the texts regarding development of communicative skills and language information which are changeable with the political changes in the country have not been up to dated. The teachers who completely depend on textbook they get complain of failing students in English by students, administration, guardians and management body. Other reference materials are not easily available everywhere nor reliable. Government provides text books in free of cast to government aided schools' students. The students and their parents are not ready to purchase reference books is challenging factor for teachers. Text book, taking the reference supporting from other reference materials is the best means to accomplish the objectives of curriculum if it is well developed.

Mukunda, Hajimohammadi and Nimechisatem (2011) have developed textbook evaluation criteria in a broad sense. They are a) general attributes: relation to syllabus and curricula methodology, suitability to learners, physical and illustration attributes and supplementary materials b) learning teaching content: general, listening, speaking, regarding, writing, vocabulary, grammar, pronunciation and exercises. We can claim that textbook has close relation to curriculum and 
syllabus. If textbook does contains the sufficient treatment regarding content and their teaching learning activities then only evaluation based on curriculum does not correlate the real objective of curriculum and content achievement of students. Only sample of consequence exercise in the textbook cannot solidify the objectives of curriculum and can it widen the teaching learning exposure which is the most important for learning and teaching foreign language.

"It was also evident that the texts students were asked to produce included variety of genres such as poems, articles, posters and leaflets, note taking, reference book entries and even a biography" (Anjaneyulu 2014, p. 190). These sorts of language production skills through writing are expected in curriculum but this is very much weak in our context. According to Tribble (2010, p. 16, cited in Anjaneyulu, 2014, p. 190), "students need to gain experience of genres that are relevant to their needs to ensure that they are able to draw on the linguistic resources that are relevant to complete a task". Our students are found poor in these matters. Nowadays pass rate of English rather than other highly failing subjects: mathematics and science is higher but learning achievement is not sufficient in secondary level up to grade 10. Math teacher from Secondary School A shared bitter experience" sir 7 students never pass mathematics in their own effort in SEE in this year even if I teach them for five years in the same class". Its direct reflection is found in grade 11 and 12 . There is higher rate in fail in English as compulsory subjects in 11 and 12 grades of the students who are from government aided school and instructed in Nepalese medium even English. Students can avoid mathematics in their 11 and 12 grade if they do not like it in other faculty rather than science but English is compulsory subject and they cannot avoid it.

\section{Evaluation in Relation to Examination System}

Evaluation, in a broad sense, is the process of judging, analyzing and deciding about teaching and learning activities based on objectives of curriculum." Generally the process used to appraise whether the learners achieve instead objectives or not is called evaluation," (Richards and Schmidt 2002, cited in Karki, 2014 , p. 91). Curriculum has objectives. Different convents are exposed to the learners with certain method. Assessment is for ensuring the learning. "Defined most simply, the assessment of learning is the means by which an institution of person determines the degree to which a person has acquired a pre-determined body or knowledge and or skill" (Muskin, 2015, P.6).

"Also assessment is meant to gauge the degree to which objectives are achieved 
and capabilities of the learners are developed, and not just to know how many snippers of facts have been memorized" (National Council of Educational Research and Training, 2006,p. 40). It means the examination evaluates not only achievement but also entire curriculum. "An examination system is a lever of considerable power: it can lead to change in the balance of control in the whole education system" (De Luca, 1994, p. 9). In the broad sense examination is the mirror and reflects the inherent essence of curriculum. The examination system can deliver the input to educational policy, curriculum, textbook writers, learners, and other concerning stakeholders with the cross-cutting evidences for their self evaluation. My participant student shared "Sir, reported is very much difficult for us; we never make it correct in the exam. Neither does sir teach it well nor is it in the textbook". Regarding this aspect of grammar, there is no well treatment; only some simple examples have been given following the texts but it needs multi level operations for its transformation. Such bitter experiences have been experienced by students refers to the insufficiency of contents in the textbook in English. Teachers in rural areas are facing the challenges of insufficiency of materials. One of my relatives who teaches English in secondary level from eastern Rukum where Kham Magar Language community people are in majority telephoned me and said "Brother, how do I teach grade 10 English? There is nothing in the textbook to be asked in the exam except questions 1 and 2. Please send me any other reference materials for it". This is the lived experience of various secondary level English teachers in rural area where people do not have the excess to modern information technology and resources through it. Even if they have, is not reliable.

After generally in summative evaluation, examination is a tool of evaluation. It is carried out to measure the students' achievement reference to curriculum goals objectively. In grade 10 as secondary education examination is carried out at national level at the end of academic years. In English it has two nature of examination: theoretical and practical. Broadly reading skills with $40 \%$ marks coverage and writing skills with $35 \%$ marks coverage out of $100 \%$ are examined in theoretical examination. "Four reading texts are used in reading skill test of them questions 1 and 2 are seen texts from the text book having 5 and 10 marks respectively. In question 1 mostly poem item and in question no. 2 reading text from book are asked. Other two questions for reading in question 3 and 4 are asked out of textbook having the mark 10 and 15 respectively. These four questions are supposed to examine students reading comprehension through fill in the blanks, vocabulary, matching items, true false, reordering items and based on text question answer items. One of my interviewee says "Most of the question items are of objective types in reading and writing then it eases students to get 
pass number with the simple answer copying trick in the examination from good students". These items are relatively objective types by nature where students can copy others answer which raises the question of reliability.

In writing, there are 6 questions ranging from question no 5 to 10 . Question number 5, 6 and 7 carrying 5, 6 and 5 marks are asked to write short paragraphs, letter writing, outline story writing, Para linguistics description, dialogue writing, or completion of outline dialogue and so on as guided writing, using the given clues and hints. In question number 8 , carrying 8 marks, students are asked to write essay or letter as free writing with given topic or situations. In question number 9 and 10 belong to grammar, question number 9 carries 6 marks and 6 grammatical items are asked to reproduce them with given instruction. Question no 10 caring 5 marks is in paragraph form each item has alternatives and one item carries 0.5 marks. This paragraph is developed in a story or narration form where items are sorted out and kept in alternative parenthesis. Sometimes students are asked not to rewrite full text. Then, they only write the correct alternative in their respective number. One of my interviewees, secondary level English teacher states:

Students in English may pass but they do not have basic language development as intended by curriculum. They pass because of our examination nature rather than their actual learning.

From these all reading and writing text items designed for SEE English test model as prepared by $C D C$, we can say that questions are relatively objective type and students can easily copy such answer from others and their real learning proficiency cannot be examined then curriculum may have the pseudo success. This achievement consistency does not abide to grade $\mathrm{XI}$ and $\mathrm{XI}$, where questions in both English subjects in compulsory and major are of more subjective nature. As in the above mentioned data show, there is the less consistency in the students' achievement in English in grade X and grade XI, XII. Learners' language skills as assumed by national curriculum are not satisfactory. There are some shortcomings with evaluation system which has not been able to evaluate various dimensions of learners' language learning in our context. Because of it there is high rate of failing in higher education in compulsory English as data mentioned above.

On practical part, the practical examination on listening and speaking carrying 15 and 10 marks respectively are administered by subject teacher of respective schools. This is in some extent only the formality. There is poor teaching and 
learning listening and speaking at schools. I have an experience that students majoring in English in bachelor under Tribhuvan University are poor in listening and speaking skill. School administration does not care about the infrastructure of lab for teaching English, listening and speaking. "Before start improving the testing modality, it is necessary to improve the teaching and learning situation of the English listening and speaking skills" (Department of Education, 2013, p. ix). There are problem in teaching listening and speaking with time cross cutting assumes unless the sufficient exposure in text books, teacher training and labs are developed it is not effective to apply and achieve the goals of English curriculum.

\section{Discussion}

After the analysis of result, there are some matters which could make two things on the phenomenon; the first is to extend the concept and the second is to offer the further research. It will also widen the further discussion. Such aspects are discussed in brief in the following categories.

Curriculum in challenge. Curriculum is the document which is based on educational policy in the state. Curriculum is supposed to regulate and guide teaching and learning materials as well as procedures. Not only is the development of curriculum but also logical implementation another important aspect of curriculum. Since curriculum is the dynamic document that should abide and lead social dynamism incorporating the contemporary social needs and exploration of knowledge. "The main reasons for curriculum development, in the context of this study are: the explosion of knowledge, and economic and technological change..."(De Luca, 1994, p. 9). Quality of curriculum depends on selected contents, their relevancy to the life of the learners and the contemporary living world. This research indicated that the students at school level in Nepal specially in community schools where English is taught as one subject and all other subjects' medium of instruction is Nepali do not have the supposed level of proficiency as aimed by curriculum.

There are some shortcomings with curriculum. Curriculum has approached communicative approach but whether is only communicative approach better to develop English language skills in context of Nepal where English is only limited inside the class room with particular subject. One interviewee from school B said:

There is no minimum satisfactory level correlation among curriculum, English textbook, teaching English subject, evaluation system, and students' achievement. Then, how can we expect quality of English teaching and learning? That's why majority of the students from community schools do not have confident in 
English. They cannot write an application even after passing SEE for job; they cannot express their ideas in English. Many problems..... One cause of students' school dropout is one subject that is English even mathematics is there.

Theses challenging experiences experienced by front line practitioners, students and teachers are unanswered questions. I have bitter experience regarding this. Once I was deployed for orientation class as teacher education in Kirtipur resource center and I questioned on such concerns the respected resource person and he accepted the reality but he shared us who listens them. "No one is responsible for such problems," he claimed. Another mentionable aspect is infrastructure of language teaching. It means for language teaching, we should have natural like language learning situation e.g. group discussion, idea sharing, debate, dialogue, language lab, field learning, and so on. Our curriculum needs such infrastructure which is not available. The schools which use English as a medium of instruction, students' English is better but not at satisfactory level in communicative competence. Students share their problem regarding communication in English Language "Sir, we think rigorously before speaking so we make many mistakes which make us avoid speaking but in writing we have different feelings and confidence". Knowledge and communicative competence are basic components for learners' better communication competence for which textbook can play the pivotal role. It is an extrinsic fact that only insufficiently developed textbook cannot be the reliable means for achieving the goal of curriculum.

Textbook reformation. A textbook has the texts including various practices and exercises to facilitate learners for self learning and evaluation of their learning to some extent as learning autonomy. The textbooks' texts are sequenced based on learning theory and help learners and teachers for effective teaching and learning. There are various demerits of textbook but it cannot be avoided. Textbook is still a valuable resource as a part of a balanced program of studies. School level English Textbook developed by CDC is not sufficient to achieve the objectives of curriculum. The contents which have been compiled in the book cannot deliver the enough exposure to the learners to develop their language level as aimed by curriculum.

Textbook has very poorly interested texts to develop reading skills. There is very much poor exposure of writing skill. All the materials are just sample. CDC has not included good texts relevance to learners living world then how can we expect that the teacher can teach better and learners can learn better. Grammatical aspect in the textbook has not been duly treated. Only few simple exercises have been mentioned in textbook which are not enough. If the students are not 
exposed ample exercise then they cannot develop their assumed grammatical competency. The textbook has not been designed for students' learning autonomy. It seems that it seeks teacher dependency learning. One student from school $A$ in grade $X$ shared her experience of the English textbook, "Sir, I heard that only two questions are asked from this book if so why should we read this book unnecessary?" It shows that students do not have hope that English textbook would help them. My experiences say that without due treatment of grammar in isolation, there is worthless effort of contextual grammar teaching. If grammar teaching is not necessary in isolation, why are Nepalese students having Nepali mother tongue poor in Nepali grammar that is somehow different in colloquial grammar.

Examination, language skills and contents. Evaluation system is integrated aspects of curriculum. In English language, in school level SEE is the national level evaluation system. When curriculum was developed, there was number based evaluation system and from 2072 B.S. new evaluation grading system was introduced. "Examination systems interact with curriculum development in a variety of ways: some effects could be described as begin or positive; others could be described as negative" (DE Luca, 1994, p. 10). This is questionable issue whether curriculum previously developed one evaluation system and without changing the objectives, contents and teaching learning strategies can the evaluation system be changed. Communicative approach has been designed in curriculum but neither do contents compiled in textbook support the communicative approach nor does the evaluation system include it. As interviewed students shared, they do not have any listening and speaking class in focused way but finally they are examined and number is sent. Similarly teachers shared, they do not have time to cover the minimum reading and writing teaching preparing for final exam. These are the lived experiences of teachers. Communicative competence in learners cannot really be evaluated through the examination system we have. Continuous assessment system and other practical and valid assessment system can be used for better evaluation.

\section{Conclusion}

From the results and discussion mentioned above, I come to conclude that English text book has tried to include all the skills and aspects of language. The text book does not have sufficient exposures which could help students to develop their language skills as intended by curriculum. This textbook looks insufficient for teacher because in context of Nepal many teachers depend on textbook. Students, in the context of Nepal learning English as a foreign language 
are evaluated on the basis of objectives designed in curriculum but students' base on textbook which does not expose sufficient materials to achieve the goals of curriculum at school level is questionable. Students do not generally concern about their curriculum and they completely rely on textbook. It is injustice for them. There are various opinions beyond the text book but it depends upon context. Textbook is mostly available and reliable sources of learning English for students as foreign language learners. It must sufficiently support their teaching. From this paper we can conclude that there is consistency between curriculum and examination even some lapses, there is gap with the textbook which could play a connectivity role between curriculum and examination. This paper and its conclusion may take the attention of concerning agencies and expert who are supposed to develop textbooks, provides feedbacks and expertise in writing English textbooks. The front line practitioners may be because they may find their experience is shared as the feeders of reformation. Further incentive researches may be conducted on how textbooks are designed, whether school English textbooks are evaluated from multiple perspectives e. g. teaching and teachability, leaning and learnability, textbook contents and their relevancy to learners live experience and so on or not. How teachers and students experience this phenomenon? What is the relation among textbook and effective English teaching-learning? What are the area of English textbook contents in the context of English teaching and learning in Nepal?

\section{References}

Anjaneyulu, T. (2014). A critical analysis of the English language textbooks in Andhar Pradesh India. ELT Research Journal , 3 (4), 181-200.

Bashyal, G. P. (2018). ELT methods and techniques in Nepai secondary schools. In B. Council, \& D. Hayes (Ed.), English langauge teaching: Research, reflection and Praactice. Kathmandu: British Council Nepal.

Bista, K. (2011). Teaching English as a foreign/second language in Nepal: Past and present. English for specific purpose, 11 (32).

Calub, C. (2018, August). Language curriculum development: An overview. Retrieved August 25, 2019, from www.researchgate.net.

Curriculum and Training Division, HSEB. (2016). Notice for enrolement. Bhaktapur, Nepal: HSEB.

Curriculum Development Center. (2067). National curriculum framework for school education in Nepal. Bhaktapur: Curriculum Development Center.

DeLuca, C. (1994). The impact of examination systems on curriculum development: An 
international study. Paris: UNESCO.

Department of Education. (2013). A study on implementation of English listening and speaking skills. Retrieved from www.deo.gov.np. August 25, 2019

Govenment of Nepal. (2015). The constitution of Nepal. Kathmandu: Nepal Law Book Publication.

Government of Nepal. (2067). National Curriculum framework for school education in Nepal. Bhaktapur: Curriculum Development Center.

Jeen Mukundan, R. H. (2011). Developing an English language textbook evalulation checklist. Contemporary Issues in Education Research , 4 (6).

Karki, M. (2014). Classroom implementation practices of the secondary level English curriculum: A case of Nepal. Journal of NELTA, 19 (1-2).

Kelly, A. V. (2004). The curriculum theory and practice. London: Sage publication.

Loop, E. (2019). Language curriculum for secondary schools. Retrieved from www. theclassroom.com., 10 15, 2019

Meidani, E. N. and Pishghadan, R. (2013). Analysis of English textbooks in the light of English as an international language (EIL): A comparative study. Interational Journal of Research Studies in Language Learning , 2 (2), 83-96.

Mukundan, J. (2007). Evaluation of English language textbooks: Some important issues for consideraton. Journal of NELTA , 12 (1 \& 2), 80-84.

Muskin, J. A. (2015). Students learning assessment and the curriculum: Issues and implications for policy, design and implementation: Current and critical issues in the curriculum and learning. Paris: UNESCO.

National Council of Educational Research and Training. (2006). Position paper national focus group on curriculum, syllabus and textbooks. New Delhi: Author.

National Examination Board (2076). Class XII result 2076 Mangal Secondary School, Kirtipur, Kathmandu. Bhaktapur, Nepal: NEB.

National Examination Board (2076). SEE result 2075 Balkumari Secondary School, Kirtipur, Kathmandu. Bhaktapur, Nepal: NEB.

Phyak, P. (2016, January 1). Local contributions of a global applied linguist: A tribute to Professor Alan Davis. Kathmandu, 3, Nepal.

Rana, K. (2018). Retention of English language tension in multilingual communities of Nepal: A review of teachers' narratives. Journal of NELTA , 23 (1-2), 40-53.

Richards, J. C. (2001). Curriculum development in language teaching. Cambridge: CUP.

Singh, J. (2015). Principles of curriculum construction for English language. Retrieved from www.teachersite.com., Aujust 15, 2019 
Tomlinson, B. (2012). Material development. In Burns, A. \&. Richards, J. C., Pedagogy and practice in second language teaching (pp. 269-278). Cambridge: CUP. 